\title{
Comparison between lateral partial turbinectomy and conchoplasty for concha bullosa
}

\author{
Atef Abd Allah Al Maraghy, Mohammed Abd Al Mon`em Yonis, Mohammed Ahmed Al \\ Sharkawy*, Alaa Gamal Eldeen Ebrahim Zewail
}

Otorhinolaryngology, Faculty of Medicine, Al- Azhar University, Egypt

Corresponding author: Mohammed Ahmed El Sharkawy, E-Mail: sharkosh@gmail.com, Mobile: 01221919061

\begin{abstract}
Background: pneumatization of the middle turbinate is common anatomic variations of lateral nasal wall, whereas rare in the superior and the inferior turbinate. Objective: to compare the efficacy of conchoplasty to lateral partial turbinectomy in the treatment of concha bullosa. Patients and Methods: this study included randomly selected 40 patients, who attended the ENT clinic at AlHussein University Hospital, Faculty of Medicine, Al-Azhar University during the period from June 2016 to November 2017.All patients have a symptomatic unilateral or bilateral concha bullosa. Patients were classified randomly into 2 groups; Group (1): 20 patients (50\%) underwent lateral partial turbinectomy. Group (2): 20 patients (50\%) underwent conchoplasty.

Results: there was complete cure or significant reduction in severity of complaints in 15 patients (75\%) who underwent LPT. In the conchoplasty group 17 patients $(85 \%)$ were significantly symptoms free at the end of the follow up period. 1 case which underwent LPT developed postoperative epistaxis requiring intervention. There were no cases of epistaxis requiring intervention in the conchoplasty group. Other complications noted in the LPT group included synechiae formation in three cases $(15 \%)$.
\end{abstract}

Conclusion: as compared to lateral partial turbinectomy, conchoplasty is an equally effective surgery in the treatment of concha bullosa with lesser incidence of complications.

Keywords: concha bullosa, middle turbinate, conchoplasty, lateral partial turbinectomy.

\section{Introduction}

Pneumatization of the nasal turbinate is known as concha bullosa, it can affect any of the turbinates, but the middle turbinate is the most commonly involved one ${ }^{(1)}$. A14\%$53.6 \%$ of concha bullosa was reported by various studies ${ }^{(2)}$. Sufficiently large concha bullosa can cause significant problems like headache, nasal obstruction and blockage of sinus drainage leading to sinonasal disease ${ }^{(3)}$. Commonly the concha bullosa contains only single air cell. Multiple air cells in a concha bullosa are relatively rare. Concha bullosa can exist unilaterally or bilaterally and it can be further classified into three groups according to the location and size of pneumatization: They are the lamellar-type, bulbous-type and extensive-type of concha bullosa. Disease process of the para nasal sinuses has the ability to affect the air cells interior to the concha bullosa. These can vary from the mucosal oedema to the formation of polyps, retention of thick mucous secretion, mucocele, pyocele and fungal infection ${ }^{(4)}$. Many surgical treatments options have been explored for the treatment of concha bullosa, especially that of the middle turbinate. These include crushing the pneumatised turbinate, partial turbinectomy, lateral turbinectomy and conchoplasty. Each of these procedures has its own advantages and disadvantages. Two of the commonly done endoscopic procedures for concha bullosa are lateral partial turbinectomy (LPT) and conchoplasty (5).

\section{Aim of the work}

To compare the results $\&$ the efficacy of chonchoplasty \& lateral partial turbinectomy in the treatment of concha bullosa. 


\section{Patients and Methods}

This prospective study was carried out on randomly selected 40 patients, who attended the ENT clinic at Al-Hussein University Hospital, Faculty of Medicine, Al-Azhar University during the period from June 2016 to November 2017. Their ages ranged from 19 to 43 years with a mean $(26 \pm 92)$, there were 26 males $(65 \%)$ \& 14 females $(35 \%)$. 22 patients $(55 \%)$ had unilateral concha bullosa \& 18 patients $(45 \%)$ had bilateral concha bullosa.34 patients $(85 \%)$ were complaining from nasal obstruction, other common complaints reported included headache in 16 patients $(40 \%)$ \& nasal discharge in 9 patients $(22.5 \%) \&$ facial pain in 9 patients $(22.5 \%)$. The duration of symptoms ranged from 1 to 10 years with mean duration $(4.52 \pm 2.52)$. Most of patients were between 1 to 5 years duration (72\%). Patients were classified randomly into 2 groups; Group (1): 20 patients (50\%) underwent lateral partial turbinectomy. Group (2): 20 patients (50\%) underwent conchoplasty. written consent was taken from every patient. Case records of all the cases were studied regarding presenting complaints, examination findings, investigation outcomes, surgical procedures done and follow up. Patients with other nasal and paranasal sinus disease together with concha bullosa were not included. Basically, two types of surgical treatments were done for the patients: lateral partial turbinectomy (LPT) and conchoplasty. These procedures were done according to the standard description by Kennedy \& Zireich ${ }^{(9)}$. For LPT, the anterior and lateral parts of the middle turbinate, including mucosa and underlying bone were removed leaving back only the inferio-medial half of the turbinate. For conchoplasty, after initial preparation of the patient, the turbinate was injected with $2 \%$ lidocaine with 1:200000 adrenaline. Mucosal incision was given at the inferior and anterior end of the turbinate in the sagittal direction. This incision was then prolonged posteriorly, as much as possible. Starting from the incision line, lateral submucosal flap was developed, leaving the bony part of the turbinate behind. After complete separation of the mucosal flap from the underlying bone, the lateral lamella of the turbinate was cut and tweezed out. The mucosal flaps were reposited on the remaining medial lamella of the bony turbinate, thus reducing the size of the turbinate, without disturbing its covering mucosa and retaining the original shape. On follow up careful recording of symptoms was done. Special note was taken regarding change in severity of symptoms after surgery. Patients then underwent examination of the nose and finally nasal endoscopy. All results and findings were collected, tabulated and analysed.

Ethical and approval statement: The study was approved by the Ethics Board of Al-Azhar University.

\section{Statistical analysis}

Data were analyzed using Statistical Program for Social Science (SPSS) version 20.0. Quantitative data were expressed as mean \pm standard deviation (SD). Qualitative data were expressed as frequency and percentage.

The following tests were done:

- Independent-samples t-test of significance was used when comparing between two means.

- Chi-square (X2) test of significance was used to compare proportions between two qualitative parameters.

- Probability (P-value)

- P-value <0.05 was considered significant.

- P-value $<0.001$ was considered as highly significant.

- P-value >0.05 was considered insignificant.

\section{Results}

This study included 40 patients who had either unilateral or bilateral concha bullosa, underwent lateral partial turbinectomy and conchoplasty for management of concha bullosa. Patients were divided into 2 groups; Group (1): 20 patients (50\%) underwent lateral partial turbinectomy and Group (2): 20 patients $(50 \%)$ underwent conchoplasty. Mean follow up period was 9 months. Minimum follow up period was 6 months and the maximum was 12 months. 1 case which underwent LPT developed post operative epistaxis in the evening of surgery which 
required reinsertion of anterior nasal packing. There were no cases of epistaxis requiring intervention in the conchoplasty group. Other complications noted in the LPT group included synechiae formation in three cases (15\%), But in all of these patients there were no complaints of nasal obstruction and synechiae were not obstructing the middle meatal opening. There was complete cure or significant reduction in severity of complaints in 15 out of the 20 patients (75\%) who underwent LPT. In the conchoplasty group 17 out of the 20 patients $(85 \%)$ were significantly symptom free at the end of the follow up period.

The analysis of comparative demography and other parameters between the two groups shows that there was no statistically significant difference between the two groups in terms of age or sex distribution and in terms of symptom severity at presentation. Even the post operative symptom improvement profile is more or less same between the two groups. However, the major difference shows in term of incidence of complications; where there were no complications in the conchoplasty group.

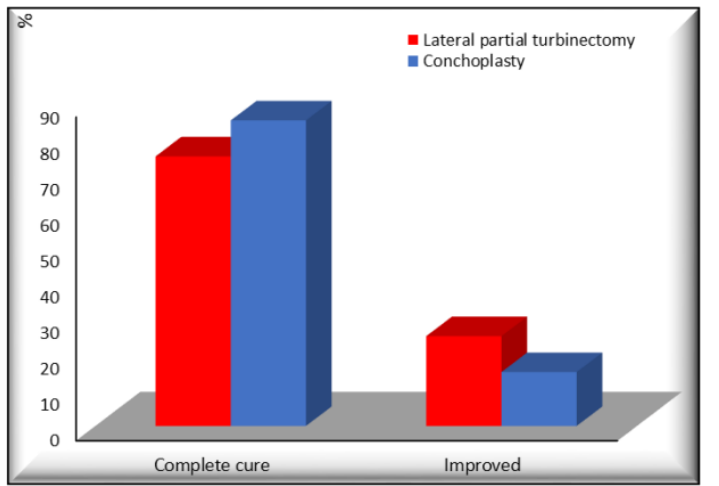

Figure(1):- shows comparison between LPT and conchoplasty groups as regard to results of surgery

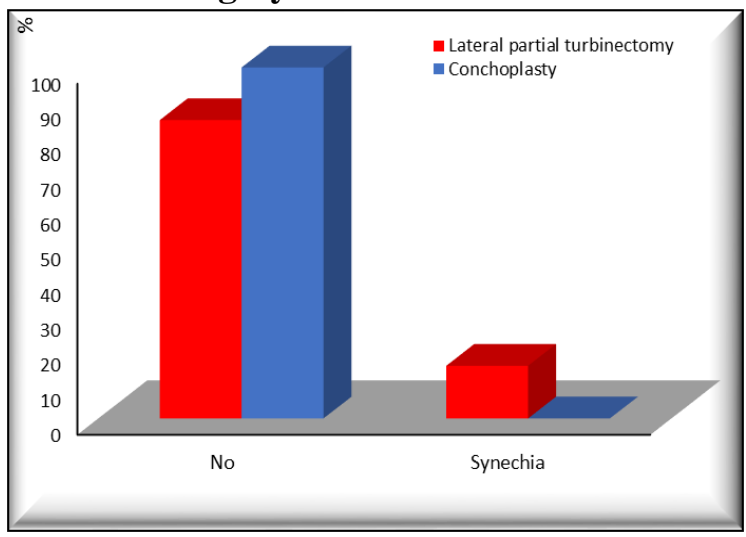

Figure (2):- shows comparison between LPT and conchoplasty groups as regard to synechia distribution

Table (1): shows comparison between lateral partial turbinectomy and conchoplasty groups as regard to post-operative symptomatic improvement

\begin{tabular}{|c|c|c|c|c|c|c|c|c|}
\hline \multirow{3}{*}{ Results } & \multicolumn{6}{|c|}{ Groups } & \multirow{2}{*}{\multicolumn{2}{|c|}{ Chi-Square }} \\
\hline & \multicolumn{2}{|c|}{$\begin{array}{ll}\begin{array}{l}\text { Lateral } \\
\text { turbinectomy }\end{array} & \text { partial } \\
\end{array}$} & \multicolumn{2}{|c|}{ Conchoplasty } & \multicolumn{2}{|c|}{ Total } & & \\
\hline & $\mathbf{N}$ & $\%$ & $\mathbf{N}$ & $\%$ & $\mathbf{N}$ & $\%$ & $\mathrm{X}^{2}$ & P-value \\
\hline $\begin{array}{l}\text { Complete } \\
\text { cure }\end{array}$ & 15 & 75.00 & 17 & 85.00 & 32 & 80.00 & & \\
\hline Improved & 5 & 25.00 & 3 & 15.00 & 8 & 20.00 & 0.625 & 0.429 \\
\hline Total & 20 & 100.00 & 20 & 100.00 & 40 & 100.00 & & \\
\hline
\end{tabular}

No statistical significant difference between the two groups as regard to post-operative symptomatic improvement, $\mathrm{P}$-value $=(0.429)$.

Table (2): shows comparison between lateral partial turbinectomy and conchoplasty groups as regard to synechia formation

\begin{tabular}{|c|c|c|c|c|c|c|c|c|}
\hline \multirow{3}{*}{ Complication } & \multicolumn{6}{|c|}{ Groups } & \multirow{2}{*}{\multicolumn{2}{|c|}{ Chi-Square }} \\
\hline & \multicolumn{2}{|c|}{$\begin{array}{ll}\begin{array}{l}\text { Lateral } \\
\text { turbinectomy }\end{array} & \text { partial } \\
\end{array}$} & \multicolumn{2}{|c|}{ Conchoplasty } & \multicolumn{2}{|c|}{ Total } & & \\
\hline & $\mathbf{N}$ & $\%$ & $\mathbf{N}$ & $\%$ & $\mathbf{N}$ & $\%$ & $\overline{\mathbf{X}^{2}}$ & P-value \\
\hline$\overline{\text { No }}$ & 17 & 85.00 & 20 & 100.00 & 37 & 92.50 & & \\
\hline Synechia & 3 & 15.00 & 0 & 0.00 & 3 & 7.50 & 3.243 & 0.072 \\
\hline Total & 20 & 100.00 & 20 & 100.00 & 40 & 100.00 & & \\
\hline
\end{tabular}


Although, post-operative synechia formation was higher in LPT group (3 out of 20) there was no statistical significant difference between the two groups, P-value $=(0.072)$.

\section{VISUAL ANALOGUE SCALE}

There is no statistically significant difference between the two groups as regard pain according to visual analogue scale. P-value $=(0.267),(0.34)$.

Table (3) shows comparison between lateral partial turbinectomy and conchoplasty groups as regard to visual analogue scale

\begin{tabular}{|c|c|c|c|c|c|c|c|c|c|}
\hline \multirow{2}{*}{\multicolumn{2}{|c|}{ V.A.S }} & \multicolumn{6}{|l|}{ Groups } & \multicolumn{2}{|c|}{ T-Test } \\
\hline & & \multicolumn{3}{|c|}{$\begin{array}{ll}\text { Lateral } & \text { partial } \\
\text { turbinectomy } & \end{array}$} & \multicolumn{3}{|c|}{ Conchoplasty } & $\mathbf{t}$ & P-value \\
\hline \multirow{2}{*}{ Pre } & Range & 4 & - & & 4 & & & \multirow{2}{*}{1.125} & \multirow{2}{*}{0.267} \\
\hline & Mean \pm SD & 7.300 & & 1.976 & 6.600 & \pm & 1.957 & & \\
\hline \multirow{2}{*}{ Post } & Range & 0 & - & & 0 & - & 2 & \multirow{2}{*}{0.967} & \multirow{2}{*}{0.340} \\
\hline & Mean \pm SD & 0.900 & \pm & 1.021 & 0.600 & \pm & 0.940 & & \\
\hline \multicolumn{2}{|c|}{ Differences } & 6.400 & & 2.011 & 6.000 & \pm & 1.947 & 0.639 & 0.527 \\
\hline \multicolumn{2}{|c|}{ Paired Test } & $<0.001^{*}$ & & & $<0.001$ & & & & \\
\hline
\end{tabular}

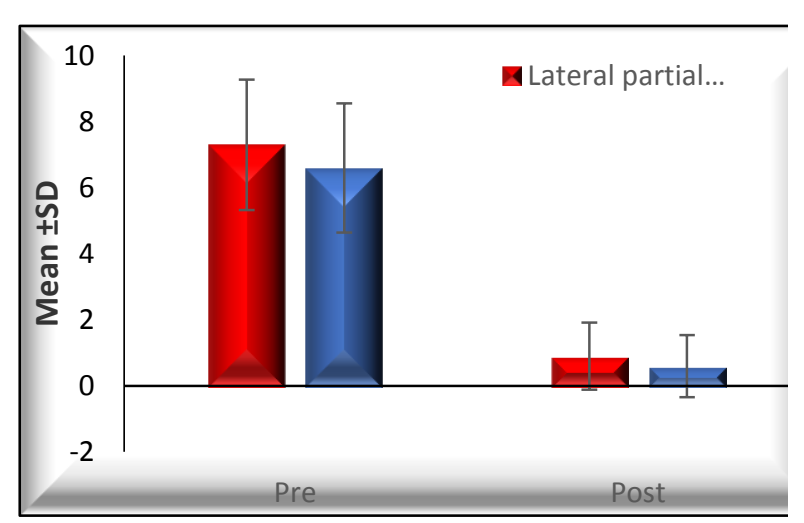

Figure (3):- shows comparison between

lateral partial turbinectomy and conchoplasty groups as regard pain according to visual analogue scale

\section{Discussion}

Concha bullosa, which is pneumatization of the turbinates, is known to affect the middle turbinate most commonly ${ }^{(2)}$. The incidence of concha bullosa in the literature ranges from $14 \%$ to $53 \%$. There is a wide range of incidences reported in the literature depending on the various parameters used to identify the concha. Extremes of incidence up to $73 \%$ have been reported (6). Pneumatization of the middle concha is divided into three groups according to the degree and localization of pneumatization: the lamellar type is the pneumatization of the vertical lamella of the concha, the bulbous type is the pneumatization of the bulbous segment, and the extensive concha bullosa is the pneumatization of both the lamellar and the bulbous parts ${ }^{(4)}$.

The degree of pneumatization defines the severity of symptoms. The first two types usually do not manifest any symptoms, but the extensive type does ${ }^{(7)}$. Comparative studies involving patients without symptoms and patients with sinusitis have reported that the concha bullosa is more frequently encountered in patients with sinusitis ${ }^{(2)}$. The indications for surgical intervention can be categorized into four groups. The first is to remove the pathologic contents of concha like infection and diseased mucosa. The second is to alleviate the nasal obstruction in extremely large cases. The third is to facilitate visualization of the ostiomeatal complex during endoscopic surgery.

The fourth is to treat the so-called "middle meatus obstructive syndrome," which results in neuralgia and pressure sensation ${ }^{(8)}$. In the present study, the main presenting symptom was nasal obstruction in 34 patients $(85 \%)$ with varying degrees of severity; with a majority of the cases having severe obstruction, other common complaints 
reported included headache in 16 patients $(40 \%)$ \& nasal discharge in 9 patients $(22.5 \%) \&$ facial pain in 9 patients $(22.5 \%)$.

In this study, the synechia formation rate is higher in LPT $(15 \%)$ than that of conchoplasty $(0 \%)$ which is better than the results of Mehta \& Kaluskar ${ }^{(10)}$ where synechia rate was $7.6 \%$ in 36 patients who underwent endoscopic turbinoplasty, which may be due to a smaller sample size of our study. Also,Dogru et al. ${ }^{(11)}$ had a similar results where Postoperative endoscopic follow-up revealed synechia in three patients (9.7\%) in conchoplasty group(31 patient) while in LPT group (100 patients), synechia was detected in 27 patients (27\%) which was statistically less common in group I compared with group II $(P<.05)$. the difference was statistically significant may be due to smaller conchoplasty group \& larger LPT group. Also, Shih et al. ${ }^{(12)}$ had a synechia rate $12.9 \%$ in turbinoplasty group and $16 \%$ in LPT group.

The results of this study come in contorary to the results of Ramadan \& Allen ${ }^{(\mathbf{1 3})}$ who had a synechia rate $9.3 \%$ (11 of 118 patient) in middle turbinate preservation group \& $5.3 \%$ (8 of 150 patients) in LPT group. Also, Havas \& Lowinger ${ }^{(\mathbf{1 4})}$ had a different result where the synechia rate was $8.5 \%$ (51 of 597 patients) in middle turbinate preservation group while $0 \%$ (0 of 509 patients) in LPT group.

In this study, there is significant reduction of pain according to VAS in both surgeries with no significant difference between two groups which coincides to some extent with Nselmo (15) where there was a significant reduction of pain after LPT. Also, Yarmohammadi et al. (16) had a significant post-operative reduction of pain in turbinoplasty group.

\section{Conclusion}

The aim of CB surgery is simply to reduce the turbinate size by using a technique with minimal surgical morbidity.As compared to lateral partial turbinectomy, conchoplasty is an equally effective surgery in the treatment of concha bullosa with lesser incidence of complication. However, Conchoplasty technique is advantageous because it results in minimal mucosal injury, plus it evenly brings the conchal walls together. Turbinoplasty technique should be considered in the surgical treatment of concha bullosa.

\section{References}

1. Hatipoglu HG, Cetin MA, Yuksel E (2005): Concha bullosa types: their relationship with sinusitis, ostiomeatal and frontal recess disease. Diagn Interv Radiol., 11(3):145-149.

2. Zinreich S, Albayram S, Benson M, Oliverio $P$ (2003): The ostiomeatal complex and functional endoscopic surgery. In: Som P, Ed. Head and Neck Imaging. 4th ed. St Louis: Mosby. Pp. 149-173.

3. Shihada $R$ and Luntz $M$ (2012): Concha bullosa mucopyocele manifesting as migraine headaches: a case report and literature review. Ear Nose Throat J., 91(5): 16-8.

4. Bolger W, Butzin C, Parsons D (1991): Paranasal sinus bony anatomic variations and mucosal abnormalities: CT analysis for endoscopic sinus surgery. Laryngoscope, 101:56-57.

5. Willner A, Lazar RH, Zalzal GH (1996): Endoscopic Treatment of concha bullosa in children. Operative Techniques in Otolaryngology - Head and Neck Surgery, 7(3):289-92.

6. Pinas-Perez I, Sabate J, Carmona A et al. (2000): Anatomical variations in the human paranasal sinus region studied by CT. J Anat., 197:221-227.

7. Har-El G and Slavit DH (1996): Turbinoplasty for concha bullosa: a nonsynechia forming alternative to middle turbinectomy. Rhinology, 34:54-56.

8. Osama AA, Hossam SE, Emad MS et al. (2012): Middle Turbinate Evacuation 
Conchoplasty in management of contact point rhinogenic headache in children. Int J Clin Pediatr., 1(4-5):115-123

9. Kennedy DW and Zinreich SJ (1988): The functional endoscopic approach to inflammatory sinus disease: Current perspectives and technique modifications. Am J Rhinol., 2:89-96.

10. Mehta $R$ and Kaluskar SK (2013): Endoscopic turbinoplasty of concha bullosa: long term results. Indian Journal of Otolaryngology and Head \& Neck Surgery, 65(2):251-4.

11. Dogru H, Tuz M, Uygur $K$ et al. (2001): A new turbinoplasty technique for the management of concha bullosa: our short-term outcomes. Laryngoscope, 111:172-175.

12. Shih C, Chin Gk, Rice DH (2003): Middle turbinate resection: Impact on outcomes in endoscopic sinus surgery. Ear Nose Throat J., 82(10):796-797.
13. Ramadan HH and Allen GC

(1995): Complications of endoscopic sinus surgery in a residency training program. Laryngoscope, 105:336-339.

14. Havas TE and Lowinger DS (2000): Comparison of functional endonasal sinus surgery with and without partial middle turbinate resection. Ann Otol Rhinol Laryngol., 109:634-640.

15. Nselmo-Lima WT, de Oliveira JA, Speciali JG et al. (1997): MT headache syndrome. Headache, 37:102-6.

16. Yarmohammadi ME, Ghasemi H, Pourfarzam S et al. (2012): Effect of turbinoplasty in concha bullosa induced rhinogenic headache, a randomized clinical trial. Journal of research in medical sciences: the official journal of Isfahan Unive 